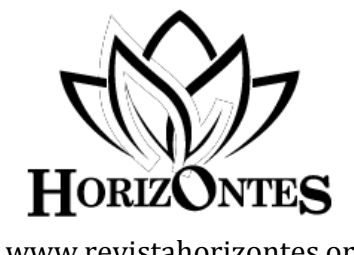

Horizontes. Revista de Investigación en Ciencias de la Educación Https://doi.org/10.33996/revistahorizontes.v3i12.83 octubre - diciembre 2019 Volumen 3 / No. 12 pp. $226-236$

www.revistahorizontes.org

\title{
Juegos posmodernos: una reflexión en torno a lo lúdico en la educación teatral
}

\author{
Postmodern games: a reflection on the playfulness in theater education
}

\author{
Penélope Hernández \\ penelopec47@gmail.com \\ Universidad Pedagógica Experimental Libertador, Venezuela
}

Recibido 5 de julio 2019 | Revisado ago-sep 2019 | Publicado 01 de octubre 2019

\section{RESUMEN}

El propósito de esta investigación fue reflexionar sobre la relevancia del universo lúdico posmoderno en la educación teatral. Se expresó la necesidad de desarrollar una visión problemática sobre la práctica escénica que genera el juego, a partir de nociones que alimentan la creación, la participación, el proceso de relectura de textos dramáticos y la representación como experiencia estética, y el imaginario de los estudiantes y docentes de teatro. La metodología fue documental, bajo un enfoque interpretativo, desde la visión hermenéutica de Gadamer y su aporte en la relación arte - juego. Se concluyó que la educación teatral posmoderna podrá idear, desde la exigencia del campo de las investigaciones artísticas, la labor de comprender la importancia del juego para promover diálogos y momentos que establezcan criterios de valoración de lo lúdico. Dichos criterios enunciarán la existencia de un conocimiento sensible desde la percepción estética del mundo. Una realidad que ofrece contextos para que el ser humano se forme estimando su expresividad en situaciones que conmocionan y promueven un aprendizaje placentero.

Palabras clave: Posmodernidad; lúdico; educación teatral; interpretación

\section{ABSTRACT}

The purpose of this research was to reflect on the relevance of the postmodern playful universe in theatrical education. The need was expressed to develop a problematic vision of the scenic practice generated by the game, based on notions that feed creation, participation, the process of rereading dramatic texts and representation as aesthetic experience, and the imaginary of students and theater teachers. The methodology was documentary, under an interpretative approach, from Gadamer's hermeneutical vision and his contribution in the art - game relationship. It was concluded that postmodern theatrical education may devise, from the requirement of the field of artistic research, the task of understanding the importance of the game to promote dialogues and moments that establish criteria for the assessment of playfulness. These criteria will state the existence of sensitive knowledge from the aesthetic perception of the world. A reality that offers contexts for human beings to be formed by estimating their expressiveness in situations that shock and promote pleasant learning.

Key words: Postmodernity; playful; theater education; interpretation 


\section{INTRODUCCIÓN}

Investigar sobre el juego teatral posmoderno obedece a una inquietud por analizar nuevas perspectivas, búsquedas y alcances que fomenten debates en las particularidades de la educación en artes escénicas, y, por ende en la comprensión de los múltiples lenguajes que se entremezclan en el universo lúdico teatral. Imbricaciones que colaboran en propiciar la necesaria transformación significativa que exige la educación en general.

Para ello, es pertinente que tanto docentes como estudiantes reconozcan estos tiempos de caos, estimación de microrrelatos, subjetivismo, incertidumbre, hibridación, y deconstrucción, aspectos para crear y abrir discusiones y planteamientos de sus implicaciones en la formación artística del ser humano actual. Indudablemente, que la posmodernidad despierta un debate en su misma definición. Discusión que conlleva a repensar los discursos y sus implicaciones en el presente. Sobre este planteamiento de complejidad e inestabilidad a la vez, es conveniente recordar lo que al respecto, en una entrevista realizada por Oñate (1987), al pensador J. F. Lyotard, se expresa sobre esta polémica:

El término posmodernidad es un falso nombre (...) Que el nombre posmodernidad, es un falso nombre, resulta evidente en cuanto se tiene en cuenta que no puede significar "lo que viene después de la modernidad", pues la palabra "moderno" significa justamente "ahora y después de ahora" será "ahora". No es el final de una cosa y el principio de otra. Eso sería absurdo, yo diría que se trata de algo que ha estado siempre inscrito en la Modernidad, como su melancolía y hasta su alegría (p. 6).
Lo antes mencionado proyecta la riqueza de la ambigüedad donde se inscribe la posmodernidad. Se plantea como riqueza y melancolía porque se expresa en una multiplicidad y no en lo unívoco, en una especie de contradicción supuesta ante la mirada de la modernidad.

Para reflexionar sobre lo lúdico en un espacio donde se valora la incertidumbre, es necesario releer con nuevos ojos el tema de la contradicción y cómo los diversos documentos así lo argumentan. Tanto lo educativo, lo artístico y lo cotidiano se enfrentan a los debates y diálogos que culturalmente ha traído la posmodernidad. Diálogos con altos y bajos, que le exigen al investigador de educación artística indagar, cambiar, imbricar, jugar y crear desde lo que antes era obviado por el poder de la razón moderna.

No se puede desestimar en el área de la educación teatral que valorar lo que antes era negado trae consigo diversas expectativas, resistencias y alteraciones en las concepciones de mundo de los seres humanos, pero desde este punto fue oportuno preguntarse ¿Dónde situarse para estimar con agudeza la visión de la posmodernidad desde lo educativo? ¿Desde el arte teatral? ¿Desde lo lúdico?

Estas interrogantes obligaron a ver desde lo periférico y desde dentro el problema que genera repensar la vinculación posmodernidad-educación- teatro-juego. Las temáticas que conformaron el proceso de investigación invitaron a distanciarse y acercarse para proporcionar un enfoque propio para la formulación de la problemática seleccionada. La vinculación con el universo del juego y la posmodernidad es ineludible, desde la discusión planteada por el pensamiento posmoderno con la razón, los metarrelatos y la continuidad temporal, ya se manifiesta una alianza con lo lúdico como una 
manera amplia y dinámica de comprender el tiempo que vivimos.

En tal sentido, Ugas (2003) manifiesta que:

Hoy se tornan difusas las certezas que dieron sustento al discurso educativo de la Modernidad. Las prácticas pedagógicas generan una inquietante sensación de fracaso; en consecuencia, plantear la posibilidad de un nuevo pensamiento pedagógico es evidenciar que en el campo educativo hay verdades puestas en cuestión" por un juego de sentidos que reclama otra manera de pensar las lides pedagógicas (p. 8).

Ante este reclamo del educador venezolano Gabriel Ugas, se abordó la temática posmodernidad, educación y juegos teatrales como una problemática que se mantiene vigente y que, de ser repensada, abre una amplia perspectiva para una formación integral y compleja, para el desarrollo de la inventiva y el entendimiento de la hibridaciones artísticas a partir de lo lúdico como espacio propicio para comprender la necesidad de una educación que prepare, desde el juego teatral, para una realidad cambiante, múltiple $\mathrm{y}$ altamente caracterizado por una pluralidad de lenguajes que se expresan a partir de la hibridación su diversidad.

De allí que el concepto de hibridación sea fundamental para comprender y sumergirse en los tejidos plurales que se manifiestan entre el pensamiento posmoderno, la educación y el juego.

Briceño (2006) expresa que con la noción de hibridación se "alude a diferentes mezclas interculturales (no exclusivamente raciales ni religiosas), a procesos de entrecruzamiento cultural que tienen lugar en las sociedades contemporáneas" (p. 56).

Así, en la presente investigación, bajo este espíritu de combinaciones múltiples, de entrecruzamientos, se reconoció que a partir de la hibridación, en el juego teatral posmoderno, se pueden combinar lenguajes artísticos que en la modernidad se consideraban de forma separada. Es así como, el juego teatral posmoderno se expresa, ante la educación actual, como un espacio plural, laberíntico, dispuesto a la experimentación.

Desde este espacio, surgieron interrogantes de investigación que fueron fundamento para el estudio que se presenta, el cual se considera como un aporte inicial para en un futuro cercano llegar a la construcción de juegos teatrales posmodernos para la educación venezolana.

¿Cuáles son los puntos de encuentro entre el pensamiento posmoderno, la educación y lo lúdico? ¿Cuáles son los elementos constitutivos de la educación posmoderna? ¿Cuáles son las relaciones entre estos elementos y el juego teatral? ¿Cuáles son los rasgos de la teatralidad posmoderna?, y ¿por qué hablar de juegos posmodernos?

Interrogantes que gestaron los siguientes objetivos:

Objetivo general: Reflexionar sobre los juegos posmodernos a la luz de las características propias de la educación teatral.

Objetivos específicos:

- Establecer los elementos característicos de la educación posmoderna

- Comprender los conceptos básicos del universo lúdico para develar su trascendencia en la enseñanza de artes escénicas.

- Analizar el juego posmoderno como espacio de creación y percepción estética.

\section{La educación posmoderna}

Expresa Giroux (1996) que una pedagogía posmoderna debe comprenderse en el marco de prácticas culturales novedosas e híbridas: 
Es necesario que los educadores entiendan cómo están surgiendo diferentes identidades en esferas que las escuelas generalmente pasan por alto. La pedagogía debe redefinir su relación con las formas modernistas de cultura, privilegio y canonicidad; como práctica cultural crítica necesita abrirse a nuevos espacios institucionales (p. 1).

Dicha apertura conlleva a entender, desde una perspectiva interpretativa, la educación. Por lo tanto, conviene reconsiderar la preocupación de Giroux, pues para él la discusión educación- posmodernidad es realmente oportuna en estos tiempos, ya que se hace inminente interpretar con nuevos ojos las distintas reorientaciones educacionales que se presentan en un espacio divergente y cambiante como el que plantea la posmodernidad.

El autor también expresa lo siguiente:

Mi interés en ampliar la manera como los educadores $\mathrm{y}$ trabajadores culturales entienden el alcance y el poder político de la pedagogía como orientadora de los jóvenes dentro de una cultura posmoderna, sugiere que no hay que idealizar ni descartar con indiferencia el posmodernismo. Por el contrario, es un discurso que debe profundizarse críticamente a fin de ayudar a los educadores a entender la naturaleza modernista de las escuelas públicas (...) También es útil para que los educadores comprendan las condiciones cambiantes de la formación de la identidad dentro de culturas mediadas electrónicamente, y la forma como esas condiciones están produciendo una nueva generación, fronteriza entre un mundo modernista de certidumbre y orden, moldeado por la cultura occidental y su tecnología impresa, y un mundo posmoderno de identidades híbridas, tecnologías electrónicas, prácticas culturales locales y espacios públicos pluralizados ( $\mathrm{p}$. 4).

El llamado de Giroux, para efectos de este estudio, implicó comprender que, especialmente la educación teatral, debe darse cuenta de manera aguda de los cambios dinámicos que la visión del mundo posmodernista posee. Así, tanto docentes como estudiantes de las artes escénicas estarán capacitados para ofrecer nuevos discursos, enfoques y espacios que superen la legitimización de la modernidad. Para ello, se debe contar con una disposición sensible, humana y amplia para apreciar las mezclas de lenguajes, por ejemplo: la palabra, la imagen, el movimiento y el sonido para ver los cambios que proponen las fusiones lúdicamente.

También, al respecto, es pertinente citar a Hargreaves (1996):

La posmodernidad es un fenómeno estético, cultural e intelectual. Engloba un conjunto particular de estilos, prácticas y formas culturales en el arte, la literatura, la música, la arquitectura, la filosofía y amplía el discurso intelectual, a modo de pastiche, collage, deconstrucción, ausencia de linealidad, mezcla de períodos y estilos, etc. (s/p).

Tomando en cuenta lo anterior, se entiende que se están investigando encuentros que se dan en un espacio posmoderno como fenómeno estético, desde su cuestionamiento a la forma unidireccional de ver el mundo. Lo que contiene la posmodernidad le ofrece al docente de hoy un momento propicio para cambiar, crear nuevas 
alternativas que valoren lo particular, lo diverso y lo plural como elementos constructores de un paradigma educativo posmoderno.

Al respecto, Terrén (1997) comenta lo siguiente:

Uno de los principales síntomas de este cuestionamiento puede verse en la hegemonía didáctica del constructivismo, pues este asume desde el principio que la objetividad es la ilusión de que hay observaciones sin observador. Esta es, en su amplia acepción, una epistemología característicamente posmoderna en cuanto tiende a reemplazar toda entidad inferida por una construcción cognoscitiva. (p. 126).

Uno de los espacios más significativos para la interpretación en la educación posmoderna lo otorga el protagonismo de la subjetividad. Su potencialidad y complejidad se manifiesta como una circunstancia que favorece la formación de estudiantes capaces de manifestarse autónomamente y reconocer la pluralidad de ideas y expresiones que se dan bajo un paradigma amplio, flexible, dialógico y lúdico.

Para García Romero (2001), en su artículo Posmodernidad: Desafíos de la Educación, la manera flexible como se admiten los fenómenos, el tiempo, el espacio también podría comprenderse como ocasión para dar paso a la apertura, a la negociación, a la comunicación múltiple. "Esta comprensión no puede ser ingenua porque la flexibilidad irracional comporta riesgos y retos permanentes. El reconocimiento de lo diferente y la ruptura con la uniformidad es también otra dimensión que puede cualificar el curso de acción de la educación" (p. 73).

Lo planteado por García Romero, en cuanto al debate educación y posmodernidad, se estima como una alternativa para entender que se pueden tomar acciones significativas para avanzar en la finalidad última de una educación acorde con un marco sociocultural variable y determinado por una pluralidad de lenguajes y culturas.

Al respecto, expresa Giroux (1996) que la pedagogía, como práctica cultural crítica, necesita abrirse a nuevos espacios institucionales en donde los estudiantes puedan experimentar y definir lo que significa ser productores culturales capaces de leer y producir textos diferentes, de entrar y salir de los discursos teóricos pero sin perder nunca de vista la necesidad de teorizar por sí mismos.

En el marco de esta autonomía otorgada por la valoración de lo particular y lo múltiple como manifestaciones de la actualidad, cabe mencionar que bajo una perspectiva lúdica, la educación posmoderna podría interrogar sobre las distintas redes complejas que se pueden tejer en un espacio capaz de trabajar con la incertidumbre, con las contradicciones aparentes para descubrir vinculaciones insospechadas entre discursos verbales y no verbales.

Este hallazgo entre opuestos acentúa la discusión acerca de la complejidad, porque ésta, para el investigador educativo Ugas (2006), es la que "articula lo desarticulado sin desconocer sus distinciones, es comprender la concurrencia, el antagonismo y la complementariedad de los contrarios al conjugar certeza con incertidumbre" (p. 12).

Desde la perspectiva lúdica, la educación posmoderna remite a replantear la implicación de los fragmentos en la totalidad de los espacios del juego. Desde este espacio, los fragmentos crean subespacios que se integran para construir realidades complejas y dinámicas que se mezclan en la búsqueda de la construcción del conocimiento. Esta mezcla se asocia a la noción de complexus, pues esta se refiere a "lo que está tejido en conjunto o lo conjuntamente entrelazado" (op.cit., p. 13). 
En tal sentido, el universo del juego en la educación posmoderna permite vincular lo que la razón desvincula. Colabora en el desarrollo de un repensar complejo, ya que busca "distinguir, reconocer lo singular y lo concreto sin desunir; integra religando en un juego dialógico: orden, desorden, organización, contexto e incertidumbre sin dar como verdad esa particular organización de un conjunto determinado" (op. cit., p. 14).

Por su parte, Colom (1997), en sus artículo "Posmodernidad y educación: fundamentos y perspectivas", hace un planteamiento acerca de la fundamentación de la posmodernidad educativa, en cuanto ésta señala lo siguiente:

En una sociedad relativizada, en que gracias a los procesos tecnológicos-informativos todo es cambiante, no habrá lugar para las grandes verdades, por lo que una formación en función de principios (valores, creencias, transcendencias, etc.) no será objeto escolar (...) Tanto importará Picasso como un comic, un graffiti como un poema de Machado (...) El futuro, en un mundo cambiante, dependerá de la capacidad de innovación, e innovar significa crear, descubrir, ampliar en definitiva el saber ( $p$. 15).

Debatir con la educación posmoderna para comprenderla como una discusión necesaria, que emerge como alternativa para la concepción de cambios trascendentes en el hecho educativo, también invitó a re-pensar lo planteado por Morin (1999) en La cabeza bien puesta:

Cada individuo debe ser plenamente consciente de que su propia vida es una aventura, incluso cuando cree que está encerrada en una seguridad; todo destino humano implica incertidumbre irreductible, inclusive la certeza absoluta, la de la muerte, ya que ignoramos su fecha. Cada uno debe ser plenamente consciente de su participación en la aventura de la humanidad que ahora tiene una rapidez acelerada, lanzada hacia lo desconocido (p. 63).

Ante lo planteado por Morin (1999), reflexionar sobre aquellos aspectos considerados menores o poco relevantes como: el riesgo, la incertidumbre y la discontinuidad de los tiempos, es un camino amplio que bien puede entenderse desde la ludicidad posmoderna. Las actividades libres del juego implican placer, aventura $y$ sorpresa. También un distanciamiento de lo acostumbrado o rutinario.

Por lo tanto, desde la posición que se asumió en esta investigación, la educación posmoderna esencialmente es lúdica, pues su paradigma como expresión cultural va más allá de modelos legitimados como únicos y eternos; se arriesga a configurar otras manifestaciones y construcciones posibles desde la flexibilidad.

Movimiento e invención serán determinantes para re-generar dimensiones educativas desde lo lúdico, pues en ese mundo hay un campo de constante construcción de infinitos, tanto del "artistapedagogo" de laferriériano, como del estudiante, y en el caso de la educación teatral, también por parte del espectador, quien construye lo que observa en escena desde su propia óptica.

Si la educación no contempla estas relaciones docente-estudiante-espectador no proporciona discusiones plurales sino monólogos, que no tienen ningún sentido ante el universo hibrido en que se vive. 
La relación con el otro es uno de los planteamientos fundamentales en la propuesta de Gadamer (1991) en $L a$ actualidad de lo bello. El hermeneuta francés, al referirse ampliamente sobre la noción de juego como una necesidad humana, discute sobre la consideración de las relaciones que genera lo lúdico.

Jugar exige siempre un "jugarcon". Incluso el espectador que observa al niño y la pelota no puede hacer otra cosa que seguir mirando. Si verdaderamente "le acompaña", eso no es otra cosa que la participatio, la participación interior en ese movimiento que se repite. Nadie puede evitar ese "jugar-con". Me parece, por lo tanto, otro momento importante el hecho de que el juego sea un hacer comunicativo también en el sentido de que no conoce propiamente la distancia entre el que juega y el que mira el juego. El espectador es, claramente, algo más que un mero observador que contempla lo que ocurre ante él; en tanto que participa en el juego, es parte de él (p. 32).

La relación juego y teatro en la educación posmoderna es un tema que debe discutirse, entre otras cosas, como una posibilidad de creación constante y de formación abierta al cambio y a las transformaciones súbitas que ocurren en estos tiempos posmodernos.

\section{MÉTODO}

Esta investigación conforme a su naturaleza se enmarcó en el paradigma cualitativo y por la consideración de sus objetivos documental. En cuanto a la investigación documental el Manual de Trabajos de Grado de Especialización y Maestría y Tesis Doctorales de la Universidad Pedagógica Experimental Libertador (2010) señala lo siguiente: El estudio de problemas con el propósito de ampliar y profundizar el conocimiento de su naturaleza, con apoyo, principalmente, en trabajos previos, información y datos divulgados por medios impresos, audiovisuales o electrónicos (p. 20).

Por consiguiente, dado que el presente estudio tiene como finalidad la reflexión e interpretación de documentos relativos al Arte teatral y a la Educación, la confluencia de visiones de diversos autores y la postura crítica del investigador fueron fundamentales. En torno a este punto Arias (2012) argumenta que este tipo de investigación se basa en buscar determinada información, organizarla para someterla a un proceso de análisis, así se realiza un nuevo aporte para el tema de estudio

Aunado a lo antes mencionado, el enfoque hermenéutico de este estudio, siguió los principios de la filosofía de Gadamer, el cual se inspira en Dilthey y Heidegger. En especial se valoró la noción de círculo hermenéutico, que se constituye como una metodología útil para las investigaciones en educación.

Sumado a esto Gadamer (1984) reivindica que es poco probable tener un conocimiento objetivo del significado de aquello se intenta comprender, ya que el ser humano está influido por su condición de ser histórico, por ello la interpretación conduce a una interacción dialéctica entre las expectativas del intérprete y el significado del texto. Se detalla a continuación los momentos de la investigación:

a) Pre-comprensión: Corresponde a la idea inicial del objeto de interpretación. La elaboración de preguntas determinaron el inicio metodológico: ¿Cuál es la idea que se tiene del texto antes de leerlo? ¿Qué se entendió del texto en la primera lectura? Al retomar la lectura ¿Cuáles son 
las nuevas ideas se tiene del texto? Este momento del proceso de investigación fue capital porque permitió reconocer la postura inicial sobre la relación educación posmoderna y arte teatral.

b) Fusión de horizontes y contextos: Para esta fase, fue importante tener en cuenta el tiempo en el que fue escrito el texto. Se debió remitir a ese momento histórico de manera que el contexto posibilite contar con una mayor comprensión de la situación. No se dejó pasar por alto nuestro tiempo ni nuestra propia situación socio-cultural, ni el horizonte de significados en el que se vive.

c) Aplicación del sentido: En este paso, se procuró conseguir una comprensión más amplia a través del hecho de aplicar un caso concreto de la docencia artística, relacionada con eso que se estudia.

En definitiva, el proceso metodológico operativo consistió en el establecimiento de pasos abiertos al cuestionamiento, el análisis de documentos y la explicación de aspectos esenciales para justificar teóricamente los problemas inherentes a la relación educación posmoderna y juegos teatrales.

\section{RESULTADOS}

\section{El Juego Teatral}

Después de lo antes planteado, es preciso revisar cómo en el juego teatral se concentra la mayoría de las funciones del universo lúdico. El juego teatral engloba las nociones de descentramiento, simulacro, ficción, diversión, espontaneidad, flexibilidad, práctica imaginaria y ficción que se han explicado con anterioridad.

Con el juego teatral se abren las posibilidades de creación, que pueden producirse en la escena como dimensión lúdica. En la dimensión lúdica teatral, se experimentan procesos de creación por parte del grupo que juega y de los espectadores que en algún momento también jugarán. A través de la teatralidad (gestos, movimientos, plasticidad, expresiones y atmósferas) se logra cuestionar jugando situaciones que llevan a ver lo que no se observa en la cotidianidad, pero que gracias al contexto de la ficción, creada por el juego teatral, pueden convertirse en experiencias estéticas.

Para Pavis (1998) el juego dramático como práctica colectiva

reúne a un grupo de "jugadores"
(y no de actores) que improvisan
conjuntamente según un tema
escogido de antemano y/o
precisado por la situación. Así
pues, en el juego dramático ya no
existe ninguna separación entre
el actor y el espectador y se
pretende, en cambio, que todo el
mundo participe en la
elaboración de una actividad
escénica (p. 266).

La inclusión de los jugadores en la dimensión lúdica teatral, se construye cuando los integrantes se sumergen en ese espacio de ficción y, de forma libre, entran en el cómo sí de personajes, argumentos y situaciones escénicas.

El simulacro del juego teatral requiere de la expresión dramática porque en ella el cuerpo, la voz y la plasticidad se encuentran para manifestarse lúdicamente. El juego teatral cobra vida a través de la expresión de sus jugadores. Sin la expresión dramática no existiría juego teatral sino otro tipo de juego.

La expresión dramática está en constante alianza con el simulacro, pues ambos construyen un proceso auténtico, donde confluyen personajes, conflictos, espacio, tiempo para mostrar las distintas búsquedas estéticas que se presentan en la dimensión lúdica escénica. 


\section{El juego teatral posmoderno}

Enmarcados en una visión compleja y dinámica de la realidad lúdica, se interpretó el juego teatral posmoderno como una oportunidad para construir lenguajes estéticos eclécticos, que permitan entender desde la ficción y la educación de las artes escénicas, distintas visiones de la importancia de la formación a artística hoy.

Al respecto, Villegas (1986) plantea que tanto en el drama de los personajes como el del tiempo y el espacio se afirma la libertad para distorsionar y valorar lo marginado. Este fenómeno es una tendencia a hacer uso del teatro para provocar discusión y nuevas maneras de ver al mundo.

Lo posmoderno en el teatro exige una lectura que establezca las demandas de la naturaleza misma del arte escénico, sus tratamientos tempo-espaciales, sus discusiones y rechazos de los discursos establecidos como mera funcionalidad $y$, sobre todo, un concepto de teatralidad que escapa de las limitaciones de una visión rígida $\mathrm{y}$, por el contrario, se manifiesta como posibilidad múltiple y abierta para cada momento teatral.

Al respecto, el profesor y dramaturgo venezolano, Sánchez Delgado (2002) destaca una consideración importante para este estudio:

Se requiere tener presente que en el siglo XX se concretó una especie de Multirracionalidad estética en el teatro, que rompió definitivamente con todo criterio escénico de carácter unívoco y homogéneo, con cualquier pretensión de enclaustrar y determinar la sensitividad del hecho teatral, bajo un único monopolio de ideas, con una sola conceptualización, en una única teoría y pragmática sobre el actor y la escena. (p.7).
El juego teatral posmoderno es un elemento nuclear de la multirracionalidad estética, debido a que es en el juego donde se puede experimentar el desafío a lo convencional, racional y estático, de una forma sensible, abierta y flexible.

En tal sentido, se consideró como parte de los resultados de la investigación que sus características fueron las siguientes:

- Configurar mundos lúdicos abiertos y no cerrados.

- Apoyar en los procesos educativos actuales el disfrute de la improvisación.

- Valorar el cuerpo, el espacio y la teatralidad en movimiento constante.

- Crear imbricaciones estéticas a través de la discontinuidad temporal/espacial.

- Experimentar las particularidades de las reglas lúdicas.

- Valorar lo multirracional como inspiración creadora.

- Considerar el acto de jugar como una manera de entender la esencia lúdica del arte teatral

- Establecer un diálogo con el discurso pedagógico para encontrarse en el espacio de la creación

Al considerar dichas características, producto de la reflexión interpretativa de los documentos y visiones sobre la educación teatral de la investigadora del presente artículo se configuró una perspectiva del juego teatral posmoderno como el ambiente propicio para que el jugador-actor- estudiante realice un trabajo que supere las expectativas del espectador. Desde lo fragmentario, el que juega, podrá armar su propia escena lúdica, desarrollará su capacidad deconstructiva y sensitiva.

El juego teatral posmoderno propicia el trabajo pedagógico estético con sensaciones, emociones, imágenes, que circulan en cada una de las situaciones o lúdica teatral que se 
presente. Ese movimiento por un momento hace que el jugador-actor-estudiante sea el centro del juego pero el otro centro lo será el espectador. Aquí se produce el descentramiento o rotación de puntos para acentuar la atmósfera lúdica como campo de libertad creadora y de formación cultural artística.

\section{CONCLUSIONES}

Algo trascendente, desde la educación posmoderna, es la posibilidad que brinda lo lúdico para inventar otras realidades, que desde el metarrelato del orden no hubiese sido posible. Crea otros discursos como alternativas de re-pensamiento y visiones dinámicas de la realidad, las cuales son tan necesarias en la actualidad que los jugadoresestudiantes-artistas van hacia una comprensión amplia del mundo que les tocó vivir, durante el proceso de aprender y desaprender para configurar escenas.

En tal sentido, el presente artículo planteó que la posmodernidad es metáfora de una etapa compleja que se manifiesta por la mezcla o hibridación de ambigüedades, contradicciones e incertidumbres que son consideradas en la educación posmoderna, según Pourtois (2008) como una "regeneración" de propuestas nuevas acordes a los cambios de la actualidad. Dichas propuestas, lo que intentan es cuestionar y mejorar la noción de para releer sus espacios sin imposiciones, sino a través de insospechadas construcciones que surgen de la interpretación, la hibridación y el diálogo entre discursos plurales.

En definitiva la educación artística escénica posmoderna a través del juego coadyuvaría a la configuración en la formación integral del individuo de una actitud creadora y transformadora con respecto a la realidad circundante del mismo, orientado dicho accionar, al establecimiento de relaciones verdaderamente estéticas, sensibles, entre estos y su entorno. Se puede decir entonces que los movimientos, imágenes, percepciones y gustos, entre otros, se plasman y manifiestan a través de las acciones, determinando la actitud creadora de docentes y estudiantes que se prestan a lo lúdico como discurso placentero educativo.

El juego teatral posmoderno se levanta, entonces, como creación de intersecciones sensibles y dispuestas para que el jugador y espectador consiga distintas formas para expresar su creación de la manera más libre y de la forma más inesperada posible. Los jugadores y espectadores podrán simular distintos roles, pues ya el juego le dio las llaves para abrir el espacio vertiginoso de la ficción.

El discurso educativo posmoderno al "conversar" con lo lúdico, en el buen sentido de la palabra, debe arriesgarse a imaginar que puede expresarse de manera distinta de acuerdo a los diferentes giros que va planteando el mundo. Un mundo donde los docentes tengan presente, a partir de su participación en los juegos posmodernos, la heterogeneidad de discursos que ofrece la multirreferencialidad de la actualidad.

\section{REFERENCIAS}

Arias, F. (2012). El Proyecto de Investigación: introducción a la investigación científica. Caracas: Episteme

Briceño, Y. (2006). Del mestizaje a la hibridación. Caracas: fundación CELARG

Colom, A. (1997). Postmodernidad y educación. Fundamentos y perspectivas. Educación i cultura (1). 7-17

Gadamer, H. (1991). La actualidad de lo bello. Barcelona: Paidós

Gadamer, H. (1984). Verdad y Método. Fundamentos de una hermenéutica filosófica. Editorial Sígueme: Salamanca

García Romero, D. (2001). Posmodernidad: Desafíos de la educación. En: Anuario Pedagógico. Centro Cultural Poveda 
Disponible

en: http://volens.be/IMG/pdf/postmodernid addesafioseducacion.pdf

Giroux, H. (1996). Educación posmoderna y generación juvenil. Nueva sociedad, 146, 148-167

Hargreaves, A. (1996). Profesorado, cultura y posmodernidad. Madrid: Morata

Morin, E. (1999). La cabeza bien puesta (Vol. 22). Buenos Aires: Nueva Visión

Oñate, T. (1987). Jean-Francois Lyotard: la tarea del pensar es pensar. Alfoz: Madrid, territorio, economía y sociedad, (39), 1520

Pavis, P. (1998). Diccionario del teatro. Barcelona: Paidós

Pourtois, J. (2008). La educación posmoderna. Caracas: Laboratorio Educativo

Sánchez Delgado, C. (2002). Dramaturgia clásica y escena posmoderna. Jornadas de estética del Departamento de Arte del
Instituto Pedagógico de Caracas

Terrén, E. (1997). Posmodernidad y educación. Política y sociedad, 24, 121139

Ugas, G. (2003). Epistemología de la Educación y la Pedagogía. TáchiraVenezuela: Taller Permanente de Estudios Epistemológicos en Ciencias Sociales

Universidad Pedagógica Experimental Libertador UPEL. (2010) Manual de Trabajos de Investigación de Especialización y Maestría en Tesis Doctorales. Fondo Editorial de la Universidad Pedagógica Experimental Libertador (FEDEUPEL) Caracas, Venezuela

Villegas, J. (1986). La interpretación de la obra dramática. Santiago de Chile: Editorial Universitaria 